\title{
Survey of Literature on Various Factors Affecting Inventory Management
}

\author{
Sarbjit Singh \\ Faculty of Business Analytics, Institute of Management Technology, India
}

Copyright $\bigcirc 2017$ by authors, all rights reserved. Authors agree that this article remains permanently open access under the terms of the Creative Commons Attribution License 4.0 International License

\begin{abstract}
Materials, manufacturing and marketing departments are the three major operating subsystems of any organization whether it is a production house or a service center, i.e. neither the goods producing organization nor the service providing organizations works without inventory, they have to maintain some inventory for smooth running of their businesses. In recent years, the study of inventory management has gained importance and lot of work has been done in the field of inventory management. This study provides insights to major work done on the various factors affecting inventory management.
\end{abstract}

Keywords Deterioration, Permissible Delay in Payments, Inflation, Time Value of Money, Demand Patterns

\section{The Important Factors Affecting Inventory Management}

\subsection{Deterioration}

Most of the physical goods undergo decay or deterioration over time. Researches in decaying or deteriorating items are important because in real life, milk, blood, drug, fruits, vegetables, foodstuffs, etc. suffer from depletion by direct spoilage while kept in store. Highly volatile liquids like gasoline, alcohol, turpentine etc. undergo physical depletion over time through the process of evaporation. The first to mention is Ghare and Schrader [1] who developed the model for an item with an exponentially decaying inventory. Since then researches in deteriorating items have become very popular. Covert and Philip [2] extended Ghare and Schrader's [1] model and obtained an economic order quantity model for a variable rate of deterioration by assuming a two-parameter Weibull distribution. S. P. Aggarwal [3] presented an order level inventory model for deteriorating items with a constant rate of deterioration which had been developed both for deterministic and stochastic demands. Shah [4] was the first to consider deterioration with complete backlogging. Miguel F. Anjos,
Russell C. H. Cheng \& Christine S. M. Currie [5](2005) proposed optimal pricing policies for perishable products Jian Li, T.C. Edwin Cheng and Shouyang Wang[6] (2007) gave an analysis of postponement strategy for perishable items by EOQ-based models

\subsection{Inflation}

In earlier days it was thought that inflation has very little effect on the total inventory cost. Since most decision makers think that the inflation does not have significant influence on the inventory policy, the effects of inflation are not considered in some inventory models. However, from a financial point of view, an inventory represents a capital investment and must compete with other assets for firms limited capital funds. Thus, it is necessary to consider the effects of inflation on the inventory system. Buzacott [7] was the first to investigate the inventory decisions under an inflationary condition in a standard EOQ. Bierman and Thomas [8] investigated the inventory decisions under an inflationary condition in a standard EOQ model. Misra [9] (1979) gave a note on optimal inventory management under inflation and developed a discount cost model in which the effects of both inflation and the time value of money are considered. Chandra and Bahner [10] developed models to investigate the effects of inflation and time value of money on a finite horizon policy. T.K Datta and Pal [11] developed a model with linear-dependent demand rates and shortages to investigate the effects of inflation and time value of money on a finite horizon policy. Ray and Chaudhari [12] gave an EOQ model with stock dependent demand, shortage, inflation and time discounting. Jamal et al [13] proposed a supply chain models for perishable products under inflation and permissible delay in payments. Yang [14] proposed another model for two warehouse partial backlogging for deteriorating items under inflation.

\subsection{Permissible Delay in Payments}

This concept is not new, although in earlier inventory models, this concept was not used. In practice, a supplier 
frequently offers a retailer a delay of fixed period (say, 30 days) for settling the account owned to him. Usually, there is no interest charged if the outstanding amount is paid within the permissible delay period. Note that the credit term in financial management is denoted as "net 30 ". However, if the payment is not paid in full by the end of the permissible delay period, then interest is charged on the outstanding amount. Goyal [15] was the first to develop an EOQ model under the condition of permissible delay in payments. He ignored the difference between the selling price and the purchase cost, and concluded that economic replenishment interval and order quantity generally increases marginally under permissible delay in payments. Although Dave [16] corrected Goyal's model by assuming the fact that the selling price is necessarily higher than its purchase price, his viewpoint did not draw much attention to the recent researchers. Aggarwal and Jaggi [17] extended Goyal's work for deteriorating products. In contrast, Jamal et al [13] amended Goyal's model by considering the difference between the unit price and unit cost, and concluded from computational results that the retailer should settle his account relatively sooner as the unit selling price increases relative to the unit cost. Recently Teng [18] provided an alternative conclusion from Goyal, and mathematically proved that it makes economic sense for a well-established sense buyer to order less quantity and take the benefits of the permissible delay more frequently. Chung-Yuan Dye [19] analyzed a deterministic inventory model developed for deteriorating items with stock dependent demand and shortages. The conditions of permissible delay in payments are also taken into consideration. Chang et al [20] ( then extended Teng's model and established an EOQ model for deteriorating items, in which supplier provides a permissible delay to the purchaser if the order quantity is greater than or equal to a predetermined quantity. Teng et-al [21] assumed the selling price is necessarily higher than the purchase cost and established an appropriate model for a retailer to determine its optimal price and lot size simultaneously when the supplier offers a permissible delay in payments. Goyal, Teng and Chang [22] Optimal proposed an ordering policy when the supplier provides a progressive scheme

\subsection{Partial Backlogging}

In most practical situations, there is a combination of above extremes, i.e. customers search for new suppliers and some may wait for the consignment. Hence there is a loss of sales, but it is only partial loss. Montogomery et al [23] was the first to introduce partial backlogging of unsatisfied demand for non-perishable items. Wee [24] studied the model of perishable items with partial backlogging of unsatisfied demand. Po-Chung Yang and Hui-Ming Wee [25] developed an inventory model with deteriorating items, quantity discount, pricing and partial backlogging Cheng-Kang Chen, et al [26] proposed a deterministic inventory model for deteriorating items with capacity constraint and time-proportional backlogging rate.

\subsection{Life Time}

Few items like medicines and processed food have fixed usage after that they are of no use, which is known as life time. Eilon and Mallaya [27] were the first authors who studied the pricing policy. They considered perishable items with maximum shelf life and no deterioration before the expiration. Hsu et al [28] proposed an Optimal ordering decision for deteriorating items with expiration date and uncertain lead time

\subsection{Concept of Two-Warehouses}

Hartley [29] proposed the concept of two warehouses, in which it is assumed that the holding costing RW is greater than that in OW. Hence, items in RW are first transferred to OW to meet the demand until the stock level in RW drops to zero and then items in OW are released. Sarma [30] developed a deterministic inventory model with infinite replenishment rate and two levels of storage. Murdeshwar and Sathe [31] extended this model to the case of finite replenishment rate. Dave [32] (further discussed the cases of bulk release pattern for both finite and infinite replenishment rates. He rectified the errors in Murdeshwar and Sathe and gave a complete solution for the model given by Sarma. In the above models the effect of deterioration was not taken into account. Sarma [33] (1987) extended his earlier model to the case of infinite replenishment rate and shortages. Pakkala and Achary [34\&35] extended the two -warehouse inventory model for deteriorating items with finite replenishment rate and shortages, taking time as discrete and continuous variable respectively. In these mentioned above, the demand rate was assumed to be constant. Subsequently, the ideas of time-varying demand and stock-dependent demand were considered by some authors, such as Goswami and Chaudhuri [36] worked on a linear trend demand, Bhunia and Maiti [37], also worked on a linear trend of demand for deteriorating items with shortages Kar et al [38] also considered a linear trend demand with finite time horizon and others Zhou [39] presented a multi warehouse inventory model for nonperishable items with time varying demand and partial backlogging. Yang [40] (2004) proposed an alternative model for determining the optimal replenishment cycle for two warehouses inventory problem under inflation. Yang [13] proposed another model for two warehouse partial backlogging rate. Niu et al [41] proposed a note on Two-warehouse inventory model with deterioration under the FIFO dispatch policy.

\subsection{Stock - Dependent Demand}

Levin et al [42] (1972) observed that "large piles of consumer goods displayed in a supermarket will lead customers to more. Yet too many goods piled up in everyone are way leave a negative impression on buyers and employees alike". Baker and Urban [43] were the first to establish an economic order quantity model (EOQ) for a 
power -form inventory-level demand pattern Datta and Pal [44] worked for deteriorating items with assumption that demand rate is a linear function of the on-hand inventory by allowing shortages, which are completely backlogged for both finite and infinite time horizons. Padmanabhan and Vrat [45] developed EOQ model for perishable items having stock dependent demand. Datta, T.K., Paul, K., [46] stock dependent demand situation with price sensitive demand rate. Chang [47] proposed a stock dependent demand model with nonlinear holding cost. Zhou et al [48] proposed inventory model for items with stock-dependent demand and two level trade credits.

\subsection{Time Dependent Demand}

Inventory problems involving time variable demand patterns have received attention from several researchers. This type of problem was first discussed by Stanley and Sivazlian. But there is no specific assumption concerning demand in the problem. Next, Silver and Meal [49] established an approximate solution technique of a deterministic inventory model with time dependent demand. Donaldson [50] developed an optimal algorithm for solving classical no-shortage inventory model analytically with linear trend in demand over fixed time horizon. Ritchie [51] gave a simple optimal solution for the EOQ with linear increasing demand. Dutta and Pal [52] considered both the deterministic and probabilistic versions of power demand pattern with variable rate of deterioration. U. Dave [53] proposed a deterministic lot-size inventory model with shortages and a linear trend in demand. Goswami and Chaudhuri [54] discussed different types of inventory models with linear trend in demand. Hariga [55] studied the effects of inflation and time value of money on an inventory model with time-dependent demand rate and shortages Bhunia et al [56] developed an inventory model of deteriorating items with lot-size dependent replenishment cost and linear trend in demand. Bhunia et al [57] extended their study to a deterministic inventory model with two levels of storage, a linear demand trend for a fixed time horizon Khanra and Chaudhuri [58] discussed an order level decaying inventory model with such time dependent quadratic demand. Zhou et al [59] gave note on an inventory model for deteriorating items with stock dependent and time varying demand rate.

\subsection{Probabilistic Demand}

Generally it is assumed in most of the inventory models that demand is either fixed or followed by some fixed pattern. In practice, there is almost some uncertainty in stocks-as prices rise with inflation, operations change, new products become available, supply chains are disrupted, competition alters, new laws are introduced, the economy varies, customers or suppliers move, and so on. From an organization's point of view, the main uncertainty is likely to be in customer demand, which might appear to fluctuate randomly or follow some long-term trend. Whitin [60] have considered probabilistic demand in his book Some Inventory Models. Naddor [61] proposed probabilistic demand pattern in his book "Inventory Systems". Warren H. Hausman and L. Joseph Thomas [62] proposed an inventory control model with probabilistic demand and periodic withdrawals Datta and Pal [63] who have considered the both deterministic and probabilistic version of the power demand pattern with variable rate of deterioration. Nita Shah [64] has given a probabilistic time scheduling model for an exponentially decaying inventory when delays in payments are permitted.. Richard E. Chatwin [65] proposed Optimal dynamic pricing of perishable products with stochastic demand and a finite set of prices Heung-Suck Hwang [66] analyzed a special case of the stochastic set covering location problem is studied for both ameliorating and deteriorating items. The objective of this study is to determine the minimum number of storage facilities among a discrete set of location sites so that the probability of each customer being covered is not less than a critical value. They have formulated this problem using the stochastic set covering problem. N. K. Mahapatra [67] presented the multi objective and single objective, inventory models of stochastically deteriorating items, in which demand is a function of inventory level and selling price of the commodity. Production rate depends upon the quality level of the items produced and unit production cost is a function of production rate. Deterioration depends upon both the quality of the item and the duration of time for storage. The time-related deterioration function follows a two parameter Weibull distribution in time. P. Brander, E. Leven, A. Segerstedt [68] examine that deterministic model can be used if demand is stationary stochastic. A dynamic programming approach from Bomberger and a heuristic method from Segerstedt are used to calculate lot sizes for four items. The production of these items is simulated with different variations in demand rates.

\section{General Survey}

Many more authors have used various other kinds of demands and factors in the field of inventory management. Most of the present authors are considering most of the factors in their present work. Some of them are Bose, Goswami and Chaudhri [69] presented their study by developing order level inventory models for deteriorating items, in which finite production rate is proportional to the time dependent demand rate. Kim [70] developed a heuristic for replenishment of deteriorating items with a linear trend in demand. S. Kar, A. K. Bhunia and M. Maiti [57] proposed an Inventory model of multi-deteriorating items sold from two shops under single management with constraints on space and investment. Aggarwal and Jain [71] presented optimal lot size inventory model with exponentially increasing demand. This situation can occur for items like computers, cellular phones and to some extent for television sets. They find the optimal schedule of replenishment which minimizes 
the total cost consisting of the ordering cost and inventory carrying cost throughout the planning horizon Teng J.T. and Chang C.T., [72] developed an economic production quantity models for deteriorating items with price- and stock-dependent demand. Tsao, Yu-Chung, Sheen and Gwo-Ji, [73] worked on dynamic pricing, promotion and replenishment policies for a deteriorating item under permissible delay in payments. Roy, T., and Chaudhari, K.S., [74] developed a production inventory model under stock-dependent demand, Weibull distribution deterioration and shortage. Shah, N.H and Shukla K.T., [75] examined a deteriorating inventory model for waiting time partial backlogging. Gour Chandra Mahata [75] had investigated the optimal retailers' replenishment decisions for deteriorating items under two levels of trade credit policy to reflect supply chain management within the economic production quantity (EPQ) framework. Liao et-al [76] worked on a deterministic inventory model for deteriorating items with two warehouses and trade credit in a supply chain system.

\section{Concluding Remarks}

This paper deals with the various factors affecting the inventory management. In this study most of the factors affecting inventory management has been considered and relevant literature survey has been provided. This study will be very beneficial for all the future research endeavors in inventory and supply chain management.

\section{REFERENCES}

[1] Ghare and Schrader., (1963) A model for exponential decaying inventory. Journal of Industrial Engineering 14(3), 238-43.

[2] Covert, R.P and G. C. Philip, 1973. An EOQ model for items with Weibull distributed deterioration. AIIE Transactions 5, 323-326

[3] Agarwal S.P. (1978). A note on an order level inventory model for a system with constant rate of deterioration, Opsearch, 15, 184-187.

[4] Shah Y.K. "An order level lot size inventory model for deteriorating items". AIIE Transactions 1977, 9(2), 108-12

[5] Miguel F. Anjos, Russell C. H. Cheng \& Christine S. M. Currie (2005) proposed optimal pricing policies for perishable products, European Journal of Operational Research. 166(1), 246-254.

[6] Jian Li, T.C. Edwin and Shouyang Wang (2007) Analysis of postponement strategy for perishable items by EOQ based models". International Journal of Production Economics, 107(1),31-38

[7] Buzacott. (1975) "EOQ with inflation for deteriorating items" Operational Research Quarterly, 1975, 26(3), 553-8.
[8] Bierman and Thomas. (1977) "Inventory decisions under inflationary condition”. Decision Sciences, 8(7), 151-55.

[9] Misra R.B. (1979) "A study of inflation effects on inventory system”. Logistics Spectrum, 9(3), 260-8

[10] Chandra MJ, Bahnar ML, (1985) The effects of inflation and time value of money on some inventory systems. International Journal of Production Economics, 23(4),723-9.

[11] Datta, T. K. and Pal, A. K. (1990) Deterministic inventory system for deteriorating items with inventory level dependent demand rate and shortages. Opsearch 27, (213-224)

[12] J. Ray and K.S. Chaudhari, (1997) An EOQ model with stock dependent demand, shortage, inflation and time discounting, International Journal of Production Economics, 53,171-180.

[13] Sarkar B.R, Jamal A.M.M and Wang S . Supply chain models for perishable products under inflation and permissible delay in payment. Computers and Operations Research 2000, 27, $59-75$

[14] Yang H.L., (2006). Two-warehouse partial backlogging inventory models for deteriorating items under inflation, International Journal of Production Economics, 103, 362-370.

[15] Goyal S. K., "Economic order quantity under conditions of permissible delay in payments". Journal of the Operational Research Society 1985, 36 (3), 335-38

[16] DAVE, U. (1985): On "Economic order quantity under conditions of permissible delay in payments" by Goyal, Journal of the Operational Research Society, 36, 1069.

[17] Aggarwal S.P., Jaggi, C.K., Ordering policies of deteriorating items under permissible delay in payments". Journal of the Operational Research Society 1995, 46, 658-662.

[18] Teng J. T. "The economic order quantity under conditions of permissible delay in payment". Journal of Operational Research Society. 2002, 53, 915-918.

[19] Chung- Yuan Dye. (2002) A deteriorating inventory model with stock-dependent demand and partial backlogging under conditions of permissible delay in payments. Opsearch, 39, 189-201.

[20] Chun-Tao Chang, Liang-Yuh Ouyang and Jinn-Tsair Teng (2003) An EOQ model for deteriorating items under supplier credits linked to order quantity. Applied Mathematical Modelling, 27(12), 983-996.

[21] Ouyang, Teng, Chuang \& Bor- Renchuang (2005) Optimal inventory policy with non-instantaneous receipt under trade credit. International J. Production Economics 98 (290-300)

[22] Teng, Chang and Goyal (2005) "Optimal Pricing and ordering policy under permissible delay in Payment". International Journal of Production Economics.97, 121-129.

[23] Montgomery, D.C., Bazarra, M.S., and Keswani, A.K. (1973). Inventory models with a mixture of backorders and lost sales. Naval Research Logistics Quarterly, 20: 255-265

[24] Wee H (1995). A deterministic lot-size inventory model for deteriorating items with shortages and a declining market. Comput. Oper. Res., 22: 345-356.

[25] Hui-Ming Wee. (1999) Deteriorating inventory model with quantity discount pricing and partial backordering 
International Journal of Production Economics, 59, 511-518.

[26] Chung-Yuan Dye, Liang-Yuh Ouyang and Tsu-Pang Hsieh (2007) Deterministic inventory model for deteriorating items with capacity constraint and time-proportional backlogging rate. European Journal of Operatinal research, 178(3), 789-807.

[27] S. Eilon and R. V. Mallaya,(1966), Issuing and pricing policy of semi-perishables in Proceedings of the 4th International Conference on Operational Research, Wiley-Interscience, New York, NY, USA.

[28] Ping-Hui Hsu, Hui Ming Wee, Hui-Ming Teng (2007) Optimal ordering decision for deteriorating items with expiration date and uncertain lead time. Computers \& Industrial Engineering, 52, (448-458).

[29] Hartley, V. R. (1976). Operations research - a managerial emphasis California. Good Year Publishing Company, 315-317.

[30] K.V.S. Sarma, (1983)'“A deterministic inventory model with two levels storage and optimum release rule" Opsearch

[31] T.M. Murdeshwar, Y.S. Sathe (1985), 'Some aspects lot-size models with two levels of storage" Opsearch

[32] V. Dave (1988) 'On the EOQ models with two levels of storage" Opsearch

[33] K.V.S Sarma (1987) A deterministic order level inventory model for deteriorating items with two storage facilities. European Journal of Operational research, 29(1), 70-73.

[34] T.P.M. Pakkala, K.K. Achary (1992), Discrete time inventory model for deteriorating items with two warehouses, Opsearch 29, 90-103.

[35] T.P.M. Pakkala, K.K. Achary (1992), A deterministic inventory model for deteriorating items with two warehouses and finite replenishment rate, European Journal of Operational Research 57, 157- 167.

[36] A. Goswami, K.S. Chaudhuri (1998), On an inventory model with two levels of storage and stock-dependent demand rate, International Journal of Systems Sciences 29, 249-254

[37] A.K. Bhunia, M. Maiti (1998), A two-warehouse inventory model for deteriorating items with a linear trend in demand and shortages, Journal of the Operational Research Society 49, 287-292. [10]

[38] S. Kar. A.K. Bhunia, M. Maiti (2001), Deterministic inventory model with two levels of storage, a linear trend in demand and a fixed time horizon. Computers \& Operations Research 28, 1315-1331.

[39] Y.W. Zhou (2003), A multi-warehouse inventory model for items with time-varying demand and shortages, Computers \& Operations Research 30, 2115-2134.

[40] Yang, H.L. (2004). Two-warehouse inventory models for deteriorating items with shortage under inflation. European Journal of Operational Research, 157, 344-356.

[41] Niu, B., \& Xie, J. (2008). A note on "Two-warehouse inventory model with deterioration under FIFO dispatch policy". European Journal of Operational Research, 190(2), 571-577.

[42] Levin, R.I., McLaughlin, C.P., Lamone, R.P., and Kottas, J.F.,
Productions / Operations Management: Contemporary Policy for Managing Operating Systems, McGraw-Hill, New York, p. $373,1972$.

[43] Baker, R.C., and Urban, T.L., (1988), A deterministic inventory system with an inventory level dependent demand rate", Journal of the Operational Research Society, 39 (1988) 823-831.

[44] Datta, T.K., and Pal, A.K., (1990), A note on an inventory model with inventory level dependent demand rate", Journal of the Operational Research Society, 41 971-975.

[45] Padmanabhan, G., and Vrat, P., (1995) EOQ models for perishable items under stock dependent selling rate. European Journal of Operational Research Society, 86 ,281-292

[46] Datta, T.K., and Paul, K., (2001), An inventory system with stock-dependent, price-sensitive demand rate, Production Planning and Control, 12 (2001) 13-20.

[47] Chang, C.-T., "Inventory model with stock-dependent demand and nonlinear holding costs for deteriorating items", Asia-Pacific Journal of Operational Research, 21 (2004) 435-446.

[48] Min Jie, Zhou, Yong-Wu and Zhap Ju, (2010) An inventory model for deteriorating items under stock-dependent demand and two level trade credit. Applied Mathematical Modeling 34(11), 2010, 3273-3285.

[49] Silver E.A. Meal H.C. (1969), A Simple modification of the EOQ for the case of a varying demand rate. Production and Inventory Management, 10(4), 52-65.

[50] Donaldson W.A. (1977), Inventory replenishment policy for a linear trend in demand-an analytical solution". Operational Research Quarterly, 1977;28,663-670 [3]

[51] Silver E.A. "A simple inventory replenishment decision rule for a linear trend in demand. Journal of Operational Research Society, 1979, 30, 71-75.

[52] Ritchie E "Practical inventory replenishment policies for a linear trend in demand followed by a period of steady demand. Journal of Operational Research Society, 1980, 31,605-613.

[53] U. Dave "On a heuristic inventory-replenishment rule for items with a linearly increasing demand incorporating shortages. Journal of the Operational Research Society, 1989 38(5), 459-463.

[54] Goswami, A. and Chaudhri, K.S (1991) An EOQ model for deteriorating items with a linear trend in demand. Journal of Operational Research Society, 42(12), 1105-1110.

[55] M. Hariga and S.K. Goyal (1995) An alternative procedure for determining the optimal policy for an inventory item having linear trend in demand, Journal of Operational Research Society, 46(4), 521- 527.

[56] [8] Bhunia, A.K., Maiti. M. (1998) A two-warehouse inventory model for deteriorating items with linear trend in demand and shortages. Journal of the Operational Research Society, 1998, 49(3), 287-292.

[57] ] S.Kar, A.K Bhunia, M. Maiti (2001) Deterministic inventory model with two levels of storage, a linear trend in demand and a fixed time horizon. Computers and Operation Research, 2001, 28, 1315-1331. 
[58] Khanra, S. and Chaudhuri, K.S. (2003) A note on an order-level inventory model for a deteriorating item with time dependent quadratic demand. Computers and Operations Research, 30, 1901-1916.

[59] Zaid T. Balki, Lakdere Benkherouf (2004)Note on an inventory model for deteriorating items with stock dependent and time varying demand rates. Computers and Operation Research, 2004, 31, 223-240.

[60] Whitin T.M., Theory of Inventory Management (Princeton University press), 1957

[61] E. Naddor, “Inventory Systems”, John Wiley \& Sons, New York, U.S.A 1966

[62] W.H. Hausman and Thomas L.J. "Inventory Control with Probabilistic demand and Periodic Withdrawals", Management Science, 1972, 18, 5, 265-275.

[63] T.K. Datta. and A.K Pal, Order level inventory system with power demand pattern for items with variable rate of deterioration, Indian Journal of Pure and Applied Maths. 19(11), (1988), 1043-1053.

[64] Nita H. Shah (1993) Probabilistic time-scheduling model for exponentially decaying inventory when delays in payments are permissible, International Journal of Production Economics, 32, 77-82.

[65] Richard E. Chatwin, (2000) Optimal dynamic pricing of perishable products with stochastic demand and a finite set of prices, European Journal of Operational Research, 125(1),149-174.

[66] Heung Suk Hwang (2004) A stochastic set-covering location model for both ameliorating and deteriorating items. Computer \& Industrial Engineering 46 (313-319)

[67] N. K. Mahapatra \& M. Malti (2005). Decision process for multi objective multi item production-inventory system-via interactive Fuzzy satisfying technique International Journal of Computers and Mathematics 49 (805-821).

[68] Par Brander, Leven \& Segerstedt, (2005) Lot sizes in a capacity constrained facility- a simulation study of stationary stochastic demand. International Journal of Production
Economics 93-94 (375-386)

[69] S. Bose, A. Goswami and K. S. Chaudhuri (1995) An EOQ model for deteriorating Items with linear time dependent demand rate and shortages under Inflation and time discounting Journal of Operational Research Society 46, (771-782)

[70] Kim, D. H. (1995) A heuristic for replenishment of deteriorating items with a linear trend in demand. International Journal of Production Economics, 39, (265-270)

[71] Aggarwal, S.P. and Jain, V. (2001), Optimal inventory management for exponentially increasing demand with deterioration, International Journal of Management and Systems, 17(1), 1-10.

[72] Teng J.T. and Chang C.T., (2005), Economic production quantity models for deteriorating items with price- and stock-dependent demand. Computers and Operations Research 32, 297-308.

[73] Tsao, Yu-Chung, Sheen and Gwo-Ji, (2008), Dynamic pricing, promotion and replenishment policies for a deteriorating item under permissible delay in payments. Computers and Operations Research 35(11), 3562-3580.

[74] Roy, T., and Chaudhari, K.S., (2009), A production inventory model under stock-dependent demand, Weibull distribution deterioration and shortage. International Federation Operational Research Society 16(3), 325-346.

[75] Shah, N.H and Shukla K.T., (2009), Deteriorating inventory model for waiting time partial backlogging. Applied Mathematical Sciences. 3(9), 421-428.

[76] Mahatma Gour Chandra, (2012), An EPQ inventory model for exponentially deteriorating items under retail partial trade policy in supply chain, Expert Systems and applications. 39(3), 3537-3550

[77] Liao Jui-Jung, Chung Kun-Jen and Huang Kuo-Nan (2013), A deterministic inventory model for deteriorating items with two warehouses and trade credit in a supply chain system. International Journal of production economics 146(2), $557-565$. 